American Journal of Environmental Sciences 7 (4): 316-330, 2011

ISSN 1553-345X

(C) 2011 Science Publications

\title{
A Critical Review of Climate Change Induced Psychosocial Impacts and Options for Strengthening Social Support Systems
}

\author{
Parnali Dhar Chowdhury, C. Emdad Haque and Graham Smith \\ Natural Resources Institute, University of Manitoba, 70 Dysart Road, \\ 303 Sinnott Building, Winnipeg, R3T 2N2, Canada
}

\begin{abstract}
Problem statement: Climate change and its associated manifestations have only recently emerged as significant threats to health faced by Canadians. The emergence of these threats has meant that Canadians are faced with increasing health-related concerns that are more frequent, more severe and occurring in communities where they have not been previously experienced. The compounding effects of change in weather patterns in communities that are heavily dependent on natural conditions for their agronomical performance could be quite severe on the mental health of farmers and other rural dwellers. Approach: Existing literature was identified for their critical review through a comprehensive serach by using web-based publications, data-base and other archival sources. Specific relevant studies were then analysed with directions for addressing the emerging psychosocial problems. An emphasis was given to the shifting nature of treament from hospital-based supports to community-based social supports. Results: In perspective of recent developments in Canada, the study offers a critical assessment of psychosocial aspects of climate change-induced extreme environmental events. In recent decades, community-based approaches and other micro-level social action interventions have gained acceptance by the concerned institutions. However, institutional supports to enhance commuity level capacity are still meager. As to identify appropriate tools, lessons for improving present systems can be drawn from the Community Emergency Response Volunteer (CERV) programs. Such tools can enhance psychosocial coping abilities through strengthening social support and enhancing the community coping capacity. Conclusion: Psychosocial effects of climate change-induced stress should be addressed from the perspective of 'model of prevention' rathern than the prevailing 'model of treatment'. Instituional changes are required to enhance the required social ties and community capacity to mitigate and cope with the psychosocial stress that disasters cause.
\end{abstract}

Key words: Climate Change, psychosocial stress, extreme weather events, mental health, social support, community capacity, higher infant mortality rates, Regional Health Authority (RHA), natural disasters, emergency preparedness

\section{INTRODUCTION}

Global climate change is a significant new development that has broadened the spectrum of environmental health threats faced by Canadians. While the number of geophysical hazards has remained approximately constant in past decades, weather-related disasters have increased from 2-4 before the mid-1970s to an annual average of 12 during the 1990s (with annual variability) (Office of Critical Infrastructure Protection and Emergency Preparedness, 2001). Climate change is expected not only to generate more frequent and intense hazards such as floods, droughts, hurricanes, heat waves and storms, but increased air pollutants and transmissions of water, food and waterborne diseases. The emergence of these threats has meant that, like citizens of many other industrialized, developed countries, Canadians are faced with increasing healthrelated concerns. The issues are related to the more frequent and severe environmental disasters that are taking place in communities where they have not been previously experienced (Health Canada, 2004).

The 2004 World Disasters Report has revealed that the number of people directly affected by "natural disasters" in Canada has risen steadily in recent years (International Federation of Red Cross and Red Crescent Societies, 2004). The total number of Canadians affected by natural disasters increased 7

Corresponding Author: Parnali Dhar Chowdhury, Natural Resources Institute, University of Manitoba, 70 Dysart Road, 303 Sinnott Building, Winnipeg, R3T 2N2, Canada 
times from $1984-1993$ to $1994-2003$, from 79,066 to 578,238 respectively. Of the 253 hazardous events listed in the Canadian Disaster Database for the period of 1990-2004, 59\% were identified as weather-related (PSEPC, 2005). Between 1985 and 1999, some 240 Canadians were killed as a result of weather-related disasters. Notable examples include the tornadoes in Barrie, Ontario (1989, 12 fatalities), Edmonton (1987, 29 fatalities) and Pine Lake, Alberta (1989, 12 fatalities) (PSEPC, 2005). In 1996, abnormally heavy rainfall led to major flooding in the Saguenay Region of Quebec, causing \$1.5 billion in financial losses and the evacuation of 15,000 people. In 1997, the Red River flood forced over 25,000 people from their homes and caused nearly $\$ 500$ million in damages. A year later, the ice storm in Ontario, Quebec and New Brunswick resulted in 28 deaths and economic losses totalling \$5 billion.

As extreme weather events have increased in frequency and intensity over the past few decades, the world-wide and Canadian demographic trend has seen a shift from a largely rural population to an expanding urban population. At the turn of the 20th century Canada was a nation of approximately 5.5 million, with $63 \%$ of the population residing in rural areas (i.e. outside centres of 1,000 population size). One hundred years later, in 2001, the population of Canada had reached over 30 million, with $80 \%$ living in urban centres (Table 1) (Canada, 2001). This trend is particularly evident in the agricultural and aboriginal communities, which are typically associated with a rural or remote northern existence. From 1996-2001 Canada's agricultural community decreased by $14.6 \%$, with the total farming population declining from 851 , 405-727,130 (Statistics Canada, 2001a). Also, one hundred years ago only 127,941 people claimed aboriginal ancestry, however by 2001 their number was claimed to be over 1.3 million (Statistics Canada, 2001b).

This geographical shift of population from largely rural to urban settings is fundamental when considering vulnerability to climate change-induced disasters. Even though rural Canadians only constitute $20 \%$ of the total population, they are still greater in sheer number today (c. 6,000,000) than they were at the turn of the 20th century (c. 3,300,000). Compared to people in urban areas, rural inhabitants tend to have a shorter life expectancy, higher death rates and higher infant mortality rates (PHAC, 2005a). The poorer health status of Canadians living in rural areas cannot be linked to one specific problem. Rather, it is a combination of personal, social, economic and environmental factors and conditions that influence health, such as income, employment and working conditions, education and training, personal health practices, equipment and the physical environment (PHAC, 2005b; Haque, 2002).

There are additional implications to rural Canadians living in remote regions which are spatially dispersed. Their geographic isolation makes them particularly more vulnerable to disasters and their effects because rural dwellers are often devoid of the same infrastructural support systems that buffer urban dwellers from the threats and impacts of disasters. The formal social support systems that are in place, such as Post-Acute Home Care (PAHC), the Regional Health Authority (RHA), the Public Health Agency of Canada (PHAC) and the Canadian Red Cross, are largely contained within urban centres and are much more difficult to access for remote populations. Also, informal social support systems, which individuals use to provide emotional or physical support to each other, are largely dependent on geographic proximity. This issue raises important questions.

In particular, what role should the Canadian government play in protecting these rural and remote inhabitants? Is it effective and/or reasonable to provide clinical-based institutional support to remotely located individuals or should support be primarily communitybased? Also, what is the most effective method of allocating support to the community level?

This study is intended to provide a critical assessment of the psychosocial impacts of climate change in Canada, particularly with respect to community capacity and social support programming. Although little research to date has examined the relationship between emerging weather patterns and the psychosocial well-being and mental health of Canadians, in particular of rural Canadians, the study draws upon existing literature to identify potential relationships and research recommendations consistent with current trends in climate change and health.

\begin{tabular}{|c|c|c|c|c|c|}
\hline Year & $\begin{array}{l}\text { Total } \\
\text { Population }\end{array}$ & Rural & Urban & $\begin{array}{l}\text { Rural } \\
(\%)\end{array}$ & $\begin{array}{l}\text { Urban } \\
(\%)\end{array}$ \\
\hline 1901 & $5,418,663$ & $3,395,299$ & $2,023,364$ & 63 & 37 \\
\hline 1911 & $7,221,662$ & $3,944,850$ & $3,276,812$ & 55 & 45 \\
\hline 1921 & $8,800,249$ & $4,446,821$ & $4,353,428$ & 51 & 49 \\
\hline 1931 & $10,376,379$ & $4,804,321$ & $5,572,058$ & 46 & 54 \\
\hline 1941 & $11,506,655$ & $5,254,239$ & $6,252,416$ & 46 & 54 \\
\hline 1951 & $14,009,429$ & $5,381,176$ & $8,628,253$ & 38 & 62 \\
\hline 1961 & $18,238,247$ & $5,537,857$ & $12,700,390$ & 30 & 70 \\
\hline 1971 & $21,568,305$ & $5,157,520$ & $16,410,785$ & 24 & 76 \\
\hline 1981 & $24,343,177$ & $5,907,254$ & $18,435,923$ & 24 & 76 \\
\hline 1991 & $27,296,856$ & $6,389,984$ & $20,906,872$ & 23 & 77 \\
\hline 2001 & $30,007,094$ & $6,098,883$ & $23,908,211$ & 20 & 80 \\
\hline
\end{tabular}

Source: Statistics Canada (2001a) 
The specific objectives of the article are three-fold: (1) to identify psychosocial impacts related to climate change-induced extreme weather events and examine community-based treatment in Canada; (2) to examine the concepts of social support and community capacity and their perceived benefits in buffering psychosocial stresses; and (3) to identify possible approaches to increase the local community level capacity in Canada to respond to and mitigate the psychosocial impacts posed by climate change.

\section{MATERIALS AND METHODS}

To attain a state of the art literature review on the topic, an extensive survey of the English language publication was made during September 2008 to August 2009. The sources of data for this study were manifold. Findings from various national, provincial and local level studies, along with various case studies and results of other empirical research work were obtained from webbased publications, journals, recent books, monographs and technical reports. These materials were mainly conducted and sponsored by governmental departments, non-governmental organizations, independent researchers and other concerned national and international agencies. These observations were substantiated by local sources such as community newsletters and bulletins, magazines and newspapers.

The Canadian national level demographic and economic data were collected from Statistics Canada (2001a) and the Canadian Institute for Health Information. It has been noted that the mainstream research on health effects of climate change emphasizes water, food, vector- and rodent-borne diseases, and to a lesser degree, the aspects of vulnerabilities to natural hazards and extreme weather (Seguin, 2008). However, the relatively 'less visible' mental health dimensions that relate to stress and well-being, have generally been ignored. In the present study, the authors attempted to logically analyze the nature of psychosocial problems, the shift in focus in treatments of mental health problems, the role of social support systems in them, and the capacities of rural communities of Canada in a sequential manner.

\section{RESULTS}

The results of the present study are organized under three sub-sections: psychosocial impact of climate change, a shift in psychosocial treatment towards community-based mental health services, and social disruption and diasters. The findings of the study thus are focussing on the particular issue of psychosocial problems in rural Manitoba, Canada that are arising from the risk of climate change-induced disasters.

Psychosocial impacts of climate change: The psychosocial consequences of climate change, particularly in relation to natural disasters, have only recently been considered within the broader realm of health research and policymaking. Up until the mid1980s, psychosocial research tended to be qualitative or based on one-time clinical observations or crude indicators of psychiatric morbidity (World Health Organization, 1992). In Canada, research has remained sporadic and frequently anecdotal, with the vast majority of literature drawing upon research conducted in the United States. At the same time, there has been a lack of consensus on the extent to which more severe disasters result in pronounced psychological sequalae. On the one hand, there has been an assumption that disasters represent catastrophic events producing adverse psychological reactions among most victims. Life threatening environmental disasters that occur suddenly are understood to be traumatic and associated with a high degree of psychological disturbance (Hutton, 2001). On the other hand, many researchers traditionally have argued that psychosocial problems following disasters are often overestimated, with difficulties occurring mainly among individuals with pre-existing mental health problems (World Health Organization, 1992, Kar, 2000).

From a human health research perspective, the psychosocial impacts of climate change and other natural risks can be effectively framed within a stress paradigm. Extreme weather events result in a number of physical, economic and social changes (or stressors) that disrupt normal living patterns and require some form of physical, social and psychological change or adjustment on the part of the individual (Fritze et al., 2008; Gruenberg, 1967). Psychological stress occurs when there is "substantial imbalance between environmental demand and the response capability of the organism" (McGrath, 1970). Lazarus and Folkman (1984) have defined stress more specifically as "a particular relationship between the person and the environment that is appraised by the person as taxing or exceeding his or her resources and endangering his or her well-being". The term stress reaction refers to the state of physiological or emotional arousal that usually results from the perception of stress or demand. When a stressor is significant, or as stressors accumulate, an individual's ability to cope and adjust may be taxed, depleting both his/her physical and psychological resources and increasing the probability of psychological distress (Bernard 2000; Lazarus and Folkman, 1984; Wheaton, 1983). 
Am. J. Environ. Sci., 7 (4): 316-330, 2011

Table 2: Public sector home care expenditure in Canada, 1988/89-1998/99

\begin{tabular}{lccccc}
\hline & Provincial government home care expenditures & & \\
Year & Home health care & Home support ('000) & Unclassified ('000) ('000) & Total ('000) & Total public sector ('000) \\
\hline $1988 / 89$ & 41.547 & 141.007 & 365.465 & 548.020 & 556.830 \\
$1989 / 90$ & 159.460 & 321.573 & 354.270 & 835.302 & 845.761 \\
$1990 / 91$ & 185.618 & 366.900 & 422.816 & 975.334 & 988.033 \\
$1991 / 92$ & 249.252 & 385.350 & 520.605 & $1,155.207$ & $1,169.072$ \\
$1992 / 93$ & 271.134 & 462.296 & 543.179 & $1,276.609$ & $1,291.953$ \\
$1993 / 94$ & 902.739 & 747.864 & 93.468 & $1,744.071$ & $1,760.628$ \\
$1994 / 95$ & 966.233 & 842.547 & 111.450 & $1,920.229$ & $1,937.863$ \\
$1995 / 96$ & 763.060 & $1,070.115$ & 145.575 & $1,78.750$ & $1,997.791$ \\
$1996 / 97$ & 783.425 & $1,146.255$ & 162.707 & $2,092.387$ & $2,114.105$ \\
$1997 / 98$ & 876.874 & $1,165.232$ & 313.305 & $2,355.411$ & $2,381.153$ \\
$1998 / 99$ & $1,092.727$ & $1,314.816$ & 327.839 & $2,735.383$ & $2,772.364$ \\
\hline
\end{tabular}

Source: Canadian Institute of Health Information, 2001 (Cited in Ballinger et al., 2001)

Climate change and extreme weather events may result in a number of stressors that are either acute or chronic in nature (Hutton et al., 2007; Haque and Burton, 2005). On the one hand, extreme weather events that occur suddenly and have violent impacts can overwhelm normal living patterns and coping mechanisms, causing heightened levels of psychological distress, which may be manifested in anxiety, depression and acute stress disorders (Dhar Chowdhury and Haque, 2011; Staab et al., 1999; Green and Lindy, 1994). On the other hand, in disasters like river floods, when onset is gradual and non-life threatening, psychological distress is likely to reflect the additive and interactive stressors that occur during recovery; for example, delays in rebuilding, financial losses and disruptions to daily living (Leaning et al., 1999). In such cases, distress tends to be manifested in either the persistence or recurrence of previously existing disorders (Smith et al. 1990) or in milder or more ephemeral difficulties commonly associated with psychological distress (Hutton, 2004; Rubonis and Bickman, 1991).

Psychosocial treatment: An emphasis towards community-based mental health services: The most effective method of treatment for psychosocial stress following a disaster has been a subject of continuous debate. Psychosocial impacts have traditionally been viewed as medicalafflictions that can be clinically diagnosed with acute symptoms and treated through psychiatric5 therapy and medicinal, drug-related treatments. Although recognized as producing profound emotional distress in individuals, the sources of stress that societal conditions created were perceived as beyond the scope of the mental health mandate (House 2002). Consequently, micro-level (individual) approaches were identified as being of more interest for research and development, as opposed to macrolevel (community) approaches (Mukherjee and Alpert,
2006). The position underlying the traditional public health framework of prevention maintained that disorders could be prevented by identifying and then eliminating the specific factors causing them. Many have since argued that this position is more practical in the field of communicable or nutritional diseases than in the prevention of mental health disorders (Bloom, 1979).

Since the de-institutionalization of the mental health system in the 1950s and 1960s, communitybased approaches and other macro-level social action interventions have gained emphasis in an attempt to influence stressors and risk factors using a wider, more holistic approach (WRHA, 2007). From 1988/891998/99, provincial government expenditures in Canada increased 25 times for home health care and nine times for home support (Table 2) (Ballinger et al., 2001). This shift in focus and philosophy was concurrent with the rise of the concept of mental health promotion as opposed to prevention, with an emphasis directed towards the community rather than institutions (Rimmer, 1999).

This approach is seen as more practical for several reasons, most notably for its relatively cheap cost, its accessibility, its efficiency and its ability to influence knowledge of coping alternatives (The Canadian Mental Health Association, 2006) asserts that mental health services should be related to the locales in which they are situated in at least five different, yet complementary ways, including:

- Whenever possible, the location of services should be the natural environment in which the service recipient normally interacts

- The entire community rather than only individuals currently experiencing serious difficulties should be considered the target of service 
- Mental health service systems should be integrated with formal and informal community helping networks

- Mental health service systems should be accountable to the communities they serve

- Mental health practice should utilize a broad range of the human resources located in the community in addition to traditional mental health professional manpower

The preference for providing mental health services in a community setting is based upon both concerns about the often debilitating effects of institutional environments and the potential benefits offered to service recipients through remaining in their normal environment (Canadian Mental Health Association, 2006). The effects of habitation in an institutional environment have been shown to often include the development of dependency, progressive loss of social and vocational competencies, loss of ability to deal competently and independently with the external world, decrease in contact with relatives and friends, stigmatization, negative self-image, withdrawal and apathy (McEwen, 1980). However, in a community setting, service recipients remain in contact with supportive social 6 systems, such as family and peer networks. These networks can offer nurturance, empathy, encouragement, information, material assistance, advice and expressions of sharing which are of central importance in recovery (Mechanic, 1999). Also, community-based service allows individuals to remain involved in everyday social affairs and activities, further enhancing the recovery process.

In Canada, community development has been described as a principal mode of approach within the health system (WRHA, 2007). Advocates, however, consistently point to the lack of support at the community level for people with mental illness (Morrow, 2010). A study by Morrow (2010) of the current state of the mental health system in the Vancouver Coastal Health ( $\mathrm{VCH})$ region in British Columbia reveals that community-based services are available, yet remain limited in their overall effectiveness. Accordingly, the mental health services available in the $\mathrm{VCH}$ region encompass a range of both hospital and community-based treatments and support options for people with mental illness, including acute care, inpatient/outpatient care, consumer and family initiatives, housing, income supports and assertive case management (Morrow, 2010). In this system, community-based services are utilized as the supports that sustain people once they have left the hospital in an attempt to keep them from re-accessing the hospital system. These community-based services are delivered by interdisciplinary mental health teams consisting of nurses, occupational therapists, physicians, psychiatrists, social workers and support staff that provide specialized services to recipients. The VCH funds non-profit and private organizations to provide a range of housing options for people with mental illness. Also, the Vancouver General Hospital and the University of British Columbia Hospital provide acute services that include inpatient programs, ambulatory clinics and consultation/liaison services.

As extensive as the VCH approach to communitybased services may appear-in fact, home care expenditure in British Columbia has steadily risen since 1982 (Ballinger et al., 2001)-there are still a wide range of individuals with mental illness who are undiagnosed and unable to access this system. Of the barriers identified, accessibility (18.2\%), availability (16.3\%) and acceptability of services $(76.3 \%$ ) are listed as major issues in having the mental health care needs met (Morrow, 2010). Similarly, mental health professionals and disaster researchers have observed that up to $75 \%$ of individuals experiencing mild disabilities and 20\% with severe disabilities tend to underutilize the psychological services available to them (Yates et al., 1989). The common hypothesis, according to the community-based approach, is that the greater one's perceived social support from informal sources, the greater the likelihood those sources will be utilized (Yates et al., 1989; Baum and Singer, 1982). Therefore, embedding mental health services to an even greater degree at the community level seems an obvious strategy to address some of the major obstacles identified.

By associating "health" with "health care" it is argued that Canadians have traditionally ignored the important role communities play in creating the conditions that support and sustain health. Although the Canadian health system is relatively successful at treating illness, it has been relatively ineffective at recognizing and stimulating action to address the broader societal determinants of health that persist throughout communities. Therefore there is an apparent need to turn the 'treatment system' into a 'health system' by emphasizing health promotion and by 7 strengthening the ability of communities to identify issues, set priorities, make decisions and take action around health issues (WRHA, 2007).

Social disruption and disasters: Reflective of the increased emphasis of Canadian health systems on community-based approaches, disaster research has 
responded with a more holistic vision that recognizes the role of social systems and the complex ways in which they can reduce psychosocial stress following a disaster (Mukherjee and Alpert, 2006; Mileti and Gailus, 2004; Mileti, 1999). According to this perspective, a disaster is a symptom of broader and more basic social problems that exist throughout a particular community or society. This differs from traditional disaster management theory, which casts disasters as static, isolated phenomena that can be controlled primarily through technological mitigation measures. This perception of human hegemony over an unchanging environment has led to short-sighted decision making and subsequently to increasing economic losses throughout the 20th century (Mileti and Gailus, 2004). In order to address this issue a shift is needed to a policy of sustainable hazard mitigation, which embraces the idea that social systems must become as dynamic and resilient as the problems that disasters impose.

Social systems are thus characterized as complex networks that exist within a physical, material environment (Mileti and Gailus, 2004; Gist and Lubin, 1989). Disasters are accordingly perceived as major environmental events that disrupt these systems by subjecting them to demands that temporarily disable social linkages. When a disaster exceeds the resilience of a social system, the affected population experiences a condition of stress. According to this perspective disasters are seen to impact the existing social systems that determine the social responses to and defences against disasters. Disasters produce a number of significant changes at the community, organizational and individual levels. In addition to increasing the stress on individuals, families and organizations, they can also affect the ability of the community and the mental health system to respond to victims' needs (Tierney, 1989). In these situations, it is common for people to perceive disasters as solely physical events or 'acts of God'; however, it is the social dimensions of disasters that ultimately determine the outcomes and consequences (Mukherjee and Alpert, 2006; Mileti and Gailus, 2004; Tierney, 1989). For example, earthquakes of similar magnitudes are not equally damaging, disruptive, or disastrous in all parts of the world. This is because some societies and communities have been more effective in mitigating earthquake hazards, for example, by creating earthquake-resistant buildings, employing effective emergency response procedures and locating hazardous materials away from populated areas. It is thus largely the decisions we make at a social level that determine our ability to cope. However, when a disaster overwhelms the social support networks, it inhibits our ability to reduce stressbuffering effects, leading to additional psychosocial stress. With this in mind, some of the major concepts that the World Health Organization (1992) has identified for consideration when linking social elements to disasters include:

- A disaster disrupts the social structure and cannot be handled by the usual socialmechanisms. This disruption may create more difficulties than physical consequences

- There are several important variables which can moderate the impacts of disasters. Theseinclude the ability of the victims to adjust psychologically, the capacity of the community structures to adapt to the crisis and the magnitude of help available

- The concept of disaster changes over time and among different cultures. In certain populations, especially in developing countries, a lengthy firsthand experience of coping with natural disasters has produced the development of specific "disaster sub-cultures", which are likely to affect the pattern of psychosocial reactions to the disaster situation

- Since catastrophic events are frequent in many developing countries, the threshold may rise for considering such an event a disaster. Nevertheless this should not lead to a failure to recognize and respond to the adverse effects that may occur. Even with repeated disasters, these effects may undermine the morale and resources of the community even further and may lessen its capacity to adjust.

In accordance with these concepts, disasters create a very high demand for a range of skills that exceed the normal response capabilities of communities (Tierney, 1989). Under high levels of stress, social systems, subunits, organizations, groups and individuals are forced to adapt. Human systems will exhibit different inherent coping capacities at all levels of complexity, which will ultimately determine their susceptibility to the disruptions caused by the disaster (Gist and Lubin, 1989). In particular, systems characterized by predisaster problems tend to be the most likely to exhibit negative effects from disaster impact, whether as psychosocial disturbances, family disorganization, or long-term community decline (Mileti and Gailus, 2004; Gist and Lubin, 1989). Tierney (1989) also contends that social disruptions that follow major disasters are the result of economic and pre-disaster political factors; the author insists that these cause more intrinsic harm than the physical destruction itself. Populations are 
therefore affected differently, according to their social status and the availability of subsequent social supports. In other words, hazardous conditions arise in relation to the social, economic and political processes that allocate assets, income and other resources in a society (Blaikie, 1994). According to this perspective, communities with weaker social networks and less economic resources are perceived as more vulnerable and having a diminished coping capacity.

It has been suggested, however, that strong social networks and high levels of social capital can ultimately complicate decision making processes and lead to conflict during disasters (Stansfeld, 2006; Buckland and Rahman, 1999). In a study by Buckland and Rahman (1999), the extent to which the level and pattern of community development reflected preparedness and response to disasters was examined in the context of the 1997 Red River flood in Manitoba. The study revealed that less socially organized communities were more willing to follow the evacuation orders given during the flood event and that the community with the highest income levels and most developed social networks saw the effectiveness limited by intra-community conflict regarding the necessity of evacuation. The results demonstrated that the level and pattern of community development affect community disaster management, but not necessarily always in a positive direction. In this scenario social capital "can be a double-edged sword in cases ofdisaster management: it can effectively mobilize people through pre-existing associations toassist one another, but it can also block or delay urgent decisions" (Buckland and Rahman, 1999). It has been argued, however, that the conflict was not necessarily the direct result of greater social organization, but the result of decentralized decision making associated with arelatively top-down approach. Conflict amongst stakeholders over the implementation of mandatory evacuation has been noted by other researchers, in particular, when public consultation and participation in emergency preparedness and responses were lacking, as well asm when command and control style leadership was imposed (Haque, 2002).

\section{DISCUSSION}

In consideration of the scale and magnitude of the emerging psychosocial problems in rural Manitoba, Canada and in other comparable geographical territories, the discussion in the following sections is purposefully geared towards seeking solutions. In particular, the asepcts of social support systems and community capacity building are critically analysed.
The need to strengthen social support systems: strengthening social support systems appears to have an obvious beneficial effect in protecting individuals from the negative psychological effects of disasters. Research has shown that enhanced social interaction between citizens, a sense of cohesion and generalized trust of other people are positively associated with perceptions of health and well-being, factors which can ameliorate the impacts of negative events at both the individual and communal levels (Mukherjee and Alpert, 2006; Lindstrom, 2004; Watenabe et al., 2004; Dunn, 2002; Subramanian et al., 2002). Also, the effect that social support has on influencing psychiatric disorder has been well documented since the nineteenth century, when Durkham (1897-1951) showed that social isolation was associated with higher rates of suicide (Stansfeld, 2006). It has also been documented that bereaved adults experience high and unexpected rates of illness and mortality in the year following the death of their spouse (Stansfeld, 2006). Thus, individuals suffering psychological stress who lack a network of friends or relatives to whom they can turn in times of emotional distress are perceived as facing a greater risk of developing lasting psychological problems (Mukherjee and Alpert, 2006; Stansfeld, 2006; Brewin et al., 2000).

The term 'social support' generally refers to an individual's social network and support systems, from which he or she can acquire information, assistance and emotional support (Jacobson, 1986; Schaefer et al., 1982). Social support has been documented as being instrumental in buffering or protecting individuals from the potentially pathogenic influence of stressful events, accounting for as much as $5-10 \%$ of the variance associated with such disorders as anxiety and depression (Lett et al., 2005). The provision of social support during a stressful episode may not only reduce its immediate severity through the generation of positive effects from affiliation, but can also encourage and facilitate coping and recovery behaviour through the provision of information and guidance in order to reduce long-term problems (Mukherjee and Alpert, 2006; Brewin et al., 2000).

However, social support is often hard to recognize in action. Rather, its presence is most often felt when it is lacking. While the presence of social support may not necessarily lessen the immediate impact of a disaster event, the absence of support will almost always be detrimental and contribute to more severe psychosocial stress (Thoits, 1995; Kaniasty and Norris, 1993). Similarly, while social support may reduce feelings of helplessness and low levels of confidence, the lack of it will more likely lead to anxiety and depression, even in 
the absence of a severe life threatening experience (Becker and Schmaling, 1991). In the event of exposure to a life threatening experience, social support has the effect of enabling the individual to perceive the event as both less threatening and relatively easier to cope with. Evidence strongly suggests that social networks have an influence on both mental and physical health and those individuals with the fewest social connections tend to experience more mental problems and have higher mortality rates (Stansfeld, 2006; Brewin et al., 2000).

As previously mentioned, the relative influence of social support in the aftermath of disasters is likely to reflect both the magnitude of the event as well as the nature of pre-existing relationships. In major disasters, particularly when they result in widespread damage and disruption, the community's capacity to cope is diminished. As people focus their energies and attention on reconstruction tasks, survivors often report decreased participation in social activities with relatives, friends, neighbours and community organizations (Bolin and Klenow, 1983). This often constitutes a loss of important day-to-day opportunities to convey and preserve a sense of support and connectedness and it causes many people to experience feelings of being alone and isolated in their problems (Kaniasty and Norris, 1993). Also, when victims see their neighbours and friends move away, disasters can dissolve the bonds linking people and communities together, lowering social capital and undermining their collective ability to cope. The need to strengthen social support systems in communities as a means to reduce psychosocial impacts after an extreme weather event is clearly evident. It is overwhelmingly evident that people lacking social support are much more vulnerable to suffering from psychosocial effects in times of great emotional need and distress. Therefore, in order to effectively address psychosocial impacts, the negative pre-existing relationships have to be dealt with before they result in negative consequences (Mileti and Gailus, 2004; Gist and Lubin, 1989). The question therefore remains how social support systems can be fully optimized inCanada and also what role each level of government should play in providing it. The answer may be that greater social support systems in Canada can only be optimized through reemphasizing the development of strong social networks and relationships at the community level. The problem however remains that the general trend in North America, since the 1970s, has been towards diminishing social ties and community cohesiveness (Putnam, 2000). Therefore it is reasonable to infer that in order to strengthen social support networks, participatory social organizations that promote co- operation and problem solving at the community level are required (Buckland and Rahman, 1999).

Community capacity building: In order to facilitate effective social support during disasters, the capacity of a community to cope with the stressors must be optimized. By increasing community coping capacity, the social support systems needed during disasters have an increased ability to buffer the stress-induced psychosocial effects. The term 'capacity' implies both containing by holding and storing and ability of mind or action. Applied to a community, 'capacity' denotes that it has the specific abilities or powers to act in particular ways and to do certain things. This term may be applied to incorporate several community functions, but in the context of community building, it refers to the way to promote or sustain the well-being of the community and its components, including individuals, informal groups, organizations, social networks and the physical environment (Chaskin, 2001). Community capacity can thus be defined as the interaction of human capital, organizational resources and social capital existing within a given community that can be used to solve collective problems and improve or maintain the wellbeing of that community (Anderson-Berry and King, 2005; Chaskin, 2001). It is therefore what allows a community to function effectively in the face of various potentially detrimental forces. Community capacity can proliferate through informal social processes and/or organized efforts by individuals, organizations and social networks that exist within the community or within larger systems of which the community is a part.

The capability to build and maintain community capacity is primarily contained within the local community, yet its connection to a larger social system ultimately determines the ability of a community to build capacity. It is difficult, however, to isolate or 'pinpoint' community capacity in action. This is because of the many ways a community can be defined and the wide range of services that it is expected to provide. According to the physical perspective, community can be defined as a geographical area that is recognized by a set of attributes associated with its location or appearance. The social perspective characterizes a community as a set of social attributes and values, such as language, class and ethnicity, which are shared by the inhabitants and commonly associated with a collective body, regardless of geographic distribution and proximity.

It is important to note that the emergency management literature has a tendency to use the term 'community' broadly without acknowledging that a community is not necessarily created by the fact of 
mere geographical proximity to a hazard or risk (Marsh and Buckle, 2001). A geographical community can be multiple sets of sub-communities, with no common value set and competing needs and desires based on the aspect for which the community evolved, for example, communities of affection or function, competition, interest, or status grouping (Marsh and Buckle, 2001). A key concept to consider is that occupants of a given community defined by spatial area are rarely homogenous, but rather are more likely involved with a mosaic of different communities that are inter-related and overlapping, as well as with other unrelated communities, which are each defined by specific common interests (Anderson-Berry and King, 2005). But what constitutes a community is constantly changing since the sense of belonging is constantly being constructed and reconstructed as people redefine what constitutes a particular community and what obligations are created through belonging (Rubin and Rubin, 2000).

In the context of increasing the capacity of a community to cope with the impacts of a disaster, there is evidence that suggests increased community cohesion may develop following a disaster (Berry and King, 2005). However, increasing evidence suggests that this tends to vary according to pre-existing social support systems and also that during the long-term recovery process community social stratification, economic viability, political motivation and structural features most often return to pre-disaster conditions (AndersonBerry and King, 2005). This tendency to revert to previous conditions has been noted as an opportunity to increase the capacity of communities to deal with future losses, but a lack of clear recovery goals at all government levels, the complexity of working with multiple administrative and service entities and an absence of institutional capacity frequently constrain any opportunity to change.

Even in rural areas, where the common definition of community may be closest to the traditional view of community, it should not be assumed that residents are of 'like mind' or are 'not in conflict' (Marsh and Buckle, 2001). For example, research on rural Canadian communities by Haque (2002) focused on the strain on volunteer capacity due to the lack of available human resources, as many community members were already performing multiple roles. The capacity of even the idealized small rural community, with its perceived strong social cohesion and high social capital, may present difficulties to the further development of community capacity building efforts due to a lack of general enthusiasm and commitment. This is compounded by the additional strain on community resources as emergency preparedness tasks are added to the other social and community duties that are already being performed. As an outcome, while there is a reasonably high level of awareness of general risks and their associated response, the awareness of rare events, such as disasters, remains generally low. As a result, a well-grounded organizational structure is absent at the community level and thus not all hazards risk-reduction models and methods are coherent (Haque, 2002; Haque and Etkin, 2007).

Tools for community capacity building: Optimizing community capacity in Canada, particular in rural Canada, is a formidable challenge. In order to address this problem, it must first be determined which levels of government should assume rightful responsibility to build and maintain community capacity. The obvious answer, when discussing community building, appears to be the local or municipal government. However, realistically all levels of government must be committed to enhancing and maintaining community capacity in an efficient and coordinated system that transcends from the federal government down into the communities. Tools are currently available in the literature and in emergency management practice that display the potential to enhance community coping capacity, in particular to disasters, at an individual or local level.

The Hazard, Impact, Risk and Vulnerability (HIRV) model is defined by Pearce (2005) as a tool for local communities and regional governments, which employs local knowledge supplemented by expert knowledge. Pearce (2005) asserts that ensuring public participation has great value in increasing the efficacy of the HIRV model process. The implementation of the model process uses a HIRV advisory committee to provide representation for stakeholders. The advisory committee is intended to provide a structure that offers several advantages, including:

- when there are multiple-stakeholders involved, it may be easier to reach consensus through an advisory committee than through a public meeting

- The honor, or responsibility, of membership encourages participants to think on behalf of the entire community rather than on behalf of their own special interest group

- The advisory committee can serve as an important vehicle for building public acceptance

Pearce (2005) highlights the importance of broadening the advisory committee by incorporating a business representative, a local resident and a community planner, along with other major community stakeholders, in order to empower vulnerable 
populations. In this way social planners benefit by gaining insights into new perspectives on how social inequities result in enhanced vulnerability during and after a disaster. In addition, greater public participation in the HIRV process increases the likelihood that there will be greater political pressure brought to bear on the resource allocation process, so that more resources can be provided for enhancing mitigation actions over and against other competing interests from other sectors. In theory, this would further increase the ability of the community to provide social and community support during a disaster.

Another tool for improving community coping capacity involves providing an organizational structure to use social capital in capacity building programs for preparedness and response planning. Examples include both the Community Emergency Response Volunteer (CERV) programs instituted in Ontario and the Community Emergency Resource Teams (CERT) in British Columbia. The CERT/CERV programs offer organizational capacity to provide training that will allow community members to be useful in times of need. The CERT/CERV programming is characterized as providing a necessary social support service through providing sources of information, tangible assistance and emotional support (Henstra, 2006). The CERT program is designed to provide communities with the capacity to survive the first $72 \mathrm{~h}$ after an event, assuming a period of relative 'chaos' and a lack of aid, which is a common emergency management situation (Simpson, 2001). While the earlier 'command and control' oriented programs, which were designed with the threat of nuclear war in mind, faced stern criticisms due to a combination of the disappearance of the threat as well as the lack of community building, the CERT model boasts greater sustainability due to the ongoing nature of natural hazard threats like earthquakes and hurricanes (Simpson, 2001). A number of major elements that Simpson (2001) identified as crucial in CERT programs are:

- Prior experience and the presence of a large scale threat: For example, Loma Prieta and Northridge in California, as well as Hurricanes Hugo andrew and Floyd in Florida

- Big Players: large cities' fire services, with resources to "try and fail" and FEMA as a source of legitimacy, particularly in terms of easing the political battle and

- Name brand" identification: more readily recognized by emergency management practitioners and researchers
With respect to evaluating the effectiveness of CERT programming, Franke and Simpson (2004) studied the role of CERT volunteer response to the 2002 Hurricane Isabel in Virginia and suggested that CERT has a great deal of potential for assisting community response efforts in a disaster, particularly in providing both a motivation for and a basic template to proceed with preparedness activities. This corresponds with the findings of Kano et al. (2005), who suggested that increased first aid training may result in increased response capacity as well as in individual members of a community looking beyond their own needs. The effect of CERT programming at the individual and household level is however less clear.

While CERT programming is designed to have trained members of the community work together as a whole and provide response capacity, the 'Strengthening Preparedness Among Neighbors' (SPAN) program is directed at providing organization for citizen efforts by arranging block groups into seven disaster response teams based on pre-existing skills and knowledge available in the neighborhood: Block Coordination, Communications, Damage Assessment, First Aid, Safety and Security, Light Search and Rescue and Sheltering and Special Needs. An example of this in a Canadian context is the Home Emergency Response Organization System (HEROS) in Coquitlam, B.C. This program entails recruiting leaders and volunteers from each neighborhood to inventory local equipment, develop a list of special-needs situations and arrange for community stockpiles. In turn, the community provides basic emergency, first aid training and financial assistance for equipment costs (Pearce, 2003). The fundamental goal of SPAN is to create stronger neighbourhoods by working at a smaller social group level and by providing a structure for people to talk, get to know and trust each other through a disaster preparedness planning network.

The HIRV, CERT and SPAN programs provide a number of well-established methods to increase community coping capacity and develop greater social capital for providing social support at the local community level through incorporating existing emergency management techniques. However, it is evident that the effectiveness in preparedness planning, particularly in terms of psychosocial impacts, is not just a matter of organizing individual, block, or communitylevel programming, but of creating a larger system of response designed to function in support of the preexisting programs and thus avoiding the kind of scenario experienced after the 1997 flood in Manitoba. 


\section{CONCLUSION}

From both a research and policy-making perspective, it is important to recognize natural hazards and emergency management as an interdisciplinary process. Natural disasters, including climate changeinduced extreme weather events, have substantial social and psychological impacts that reflect not only impact characteristics (e.g., magnitude and severity) but also pre-existing psychological, social and economic vulnerabilities which influence coping and adaptation capacities. However, more in-depth research addressing the psychosocial aspects of climate change is essential to raise awareness among policy-makers and to develop more integrated and comprehensive adaptation strategies (Allen, 2006).

An obvious prerequisite to prevent adverse health effects of climate change and extreme environmental events is public knowledge about the nature of the risk (Kovats and Haines, 2005). Environmental and emergency management in Canada has traditionally relied on fairly generic public awareness and education campaigns to promote hazards awareness and preparedness. Research is now revealing significant social differentiation in response to warning groups and the need for alternative motivators to change their behaviour (Haque et al., 2004). Both risk perception and behaviour modification, which underlie coping and adaptation to hazards of all types, reflect a complex matrix of factors that include the perceived probability of economic loss, financial security, residential proximity and trust in authorities (Smith and Petley, 2009; Williams et al., 1999). This is further underlain by personal knowledge and experiences, beliefs and values, language, social and cultural norms and personality traits such as locus of control (internal or external) (Haque et al., 2004). These are particularly relevant in a multicultural country like Canada and especially important to a city like Toronto in which $36 \%$ of all new immigrants and $40 \%$ of refugee claimants annually settle (Strike et al., 2002).

Increasingly, there is recognition that stakeholder involvement is a necessary component to effectively mitigate and reduce hazards of all types. Although the formulation of adaptation policies, strategies and programs is the responsibility of policy-makers and decision-makers at more senior levels of government, local communities carry out the actual delivery of programs. The threat of climate change specifically, but also health as seen from a broad perspective, requires the effective transfer of research and knowledge into mitigation and adaptation strategies. Stakeholders have to be actively engaged and their perspectives incorporated into information regarding climate change variables and impacts/effects (Chiotti et al., 2005). Increasing emphasis has been placed upon grass root programs and regional downscale scenarios to ensure that stakeholders perceive information as useful and meaningful.

It is necessary to note that the Canadian Climate Change Action Fund-Public Education and Outreach Program funded 152 projects between 1998 and 2001. Key accomplishments included the formation of partnerships with 115 environment groups, 100 educational institutions, 38 municipalities and federations; the training of at least 600 teachers and 2,000 community members; the development of 39 education kits for different stakeholders; and the development of 27 websites. Notable program examples include the 'New Brunswick Environmental Network', which aimed to build capacity among 75 citizen groups to take action on climate change at the local level and 'Climate Wise', an Albertan community outreach initiative designed to identify barriers inhibiting citizens from taking action and stimulate behavioral change (Statistics Canada, 2001a). In addition, disaster management programming, such as the CERT and CERV programs across the country, are beginning to unfold on the ground. Coupled with hazard analysis techniques such as HIRV analysis and supported by programming like the PHAC Community Capacity Building Tool, disaster management is, to some extent, making the link between higher levels of government and grass-roots participation. A more explicit recognition of the mutual linkages between climate change and disaster management in terms of adaptation, coping and psychosocial stress, particularly with respect to developing community and social support, would be beneficial and would further adaptation objectives for both areas.

Despite this increasing attention to population health and social cohesion in the broader health domain, to date there has not been a systematic analysis in Canada of how mainstream environmental and emergency management programming either enhances or erodes community resiliency; social support is treated as an afterthought or by-product of programs supporting risk reduction. From a research perspective, then, there is now a growing opportunity to link psychosocial factors into natural hazards research and emergency management policy and decision-making processes. Currently there is a clear lack of Canadian research addressing psychosocial aspects of natural hazards in general, with much of the literature being descriptive in nature. In particular, research emphasizing rural/remote populations is lacking. Research has also tended to take the form of short-term 
studies focusing on either the immediate psychological impacts or the efficacy of implemented psychosocial interventions, with little attention given to longer-term impacts beyond a two to three year period.

Overall, our critical assessment of climate change and its associated aspect of psychosocial stress (such as impact and adaptation), the role of social support and community capacity to manage emergencies and disasters have led to a number of policy recommendations. They are summarized in the following.

There is a need to develop a body of Canadian research to address the psychosocial aspects of climate change-induced extreme weather events, both qualitatively and quantitatively. There is also an apparent need to create a framework for studying and discussing the social and psychological aspects of climate change. This should be consistent with broader climate change frameworks being developed in Canada. It should examine potential adverse impacts of climate change but also vulnerabilities and patterns of coping and adaptation, based on a population health perspective and taking into account differences across regions and populations. Given the cultural diversity of Canada, increased attention can also be given to cultural and communication dimensions that influence not only coping and adaptation, but also the effectiveness of warnings and preparedness education and outreach programs.

Psychosocial research should be based on a multidisciplinary approach that provides a heuristic perspective through which coping and adaptation processes and conditions can be examined. Disciplines as diverse as psychology, social work, sociology, community development, health promotion, demography, epidemiology and emergency management all have relevance to ensuring a more indepth and comprehensive research approach to the Psychosocial aspects of climate change. Because interdisciplinary work is often hampered by a lack of shared language and differences in methodologies, the need for a common framework is further emphasized.

There is a need to undertake longitudinal studies, whenever possible, across different demographic groups (children, elderly, urban, rural and outdoor workers), to account for the gradual and accumulative effects of climate change. Although a number of environmental threats such as hurricanes or tornadoes may have potentially traumatic impacts, the effects of events like droughts are more diffused and often become apparent only over longer-term observations. In addition, it is important to identify adaptation processes and patterns by examining how different Communities learn to cope and adapt to the associated impacts caused by the events.

In northern communities, increased attention should be given to the interaction between climate change and traditional livelihood activities, lifestyles and health practices. Although considerable research has already been undertaken to examine economic and community impacts of climate change in northern communities, there remains a lack of research which might begin to frame these impacts in a psychological perspective (Haque et al., 2006). Studies on building resiliency and coping capacity to reduce the psychological stress associated with these impacts should also be undertaken. The psychosocial aspects of climate change and disasters should not be viewed apart or distinct from mainstream environmental management or emergency management programs. There is a now a growing recognition that the transfer of research and knowledge into community-level mitigation and adaptation strategies requires the meaningful engagement of stakeholders. While many climate change education programs have integrated a grassroots perspective that encourages public participation, as exemplified by the Canadian Climate Change Action Fund-Public Education and Outreach Program, they have not necessarily emphasized enhancing social and communal structures that would promote psychological coping and adaptation. The degree to which both environmental and emergency management policy and decision-making encourage community participation, mutual aid networks and cooperative strategies of communication will ultimately determine the capacity of communities to cope with both the physical and psychological aspects of climate change and disasters. Moreover, the manner in which people perceive, interpret and respond to climate change and extreme environmental events-factors which underlie preparedness and response activities-is very much a psychological process that deserves further attention in the area of climate change.

Very little attention or effort has hitherto been put towards understanding how climate. Change-induced extreme weather events will affect Canadians, in particular rural inhabitants, at a psychosocial level. As this study attempted to examine how to minimize or treat psychosocial stress, it is evident that the Canadian mental health system is still largely based on a model of treatment as opposed to prevention. A more holistic, preventative approach would recognize the benefits of strengthening social support systems through increased community capacity and emphasizing community- 
based mental health treatment. However, as previously indicated, the general trend in North America is towards diminishing social ties and community cohesiveness, which suggests that this problem will only get worse. Therefore, it is imperative to effectively identify methods for increasing social ties and community capacity, in an attempt to strengthen our social support systems and thereby increase our ability, within an emergency preparedness framework strategy, to cope with the psychosocial stress that disasters cause.

\section{REFERENCES}

Allen, K.M., 2006. Community-based disaster preparedness and climate adaptation: local capacity-building in the Philippines. Disasters, 30: 81-101. DOI: 10.1111/J.1467-9523.2006.00308.X

Anderson-Berry, L. And D. King, 2005. Mitigation of the impact of tropical cyclones in Northern Australia through community capacity enhancement. Mitigat. Adaptat. Strat. Global Change, 10: 367-392. DOI: 10.1007/S11027-0050052-9

Ballinger, G., J. Zhang and V. Hicks, 2001. Home care estimates in national health expenditures. Canadian Institute for Health Information.

Baum, A. and J.E. Singer, 1982. Handbook of psychology and health. L. Erlbaum Associates, Hillsdale, Hillsdale, N.J.

Bernard, L.L., 2000. Husband's and Daughter's Role Strain during Breast Cancer Patient Hospice Caregiving and Bereavement Adjustment. M.Sc. Thesis. University Of North Texas, pp: 1-63.

Blaikie, P.M., 1994. At Risk: Natural Hazards, People's Vulnerability and Disasters. 1st Edn., Routledge, London, ISBN-10: 0415084776, pp: 284.

Bloom, B.L., 1979. Prevention of mental disorders: Recent advances in theory and practice. Commun. Mental Health J., 15: 179-191. DOI: 10.1007/BF00766006

Bolin, R. and D.L. Klenow, 1983. Response of the elderly to disaster: An age-stratified analysis. Int. J. Aging Hum. Dev., 16: 283-296. DOI: 10.2190/Mqeg-Yn39-8d5v-Wkmp

Brewin, C.R., B. Andrews and J.D. Valentine, 2000. Meta-analysis of risk factors for posttraumatic stress disorder in trauma-exposed adults. J. Consult. Clin. Psych., 68: 748-766. DOI: 10.1037/0022-006X.68.5.748

Buckland, J. and M. Rahman, 1999. Community-based disaster management during the 1997 Red River flood in Canada. Disasters, 23: 174-191. DOI: 10.1111/1467-7717.00112
Chaskin, R.J., 2001. Building Community Capacity. 1st Edn., Aldine Transaction, New Brunswick, N.J., ISBN-10: 0202306402, pp: 268.

Chiotti, Q., R. Finlay and M. Pattendon, 2005. Developing a more adaptive response to climate change: An ENGO perspective. Paper presented at Adapting to Climate Change in Canada 2005: Understanding Risks and Building Capacity. Montreal, May 6.

Dhar Chowdhury, P., C.E. Haque, 2011. Risk Perception and Knowledge Gap between Experts and Public: Aspects of Flood Hazards Management in Canada. J. Environ. Res. Dev., 5: 1017-1022.

Dunn, J., 2002. Housing and inequalities in health: A study of socioeconomic dimensions of housing and self reported health from a survey of Vancouver residents. J. Epidemiol. Commun. Health, 56: 671681. DOI: 10.1136/JECH.56.9.671

Franke, M.E. and D.M. Simpson, 2004. Community Response to Hurricane Isabel: An Examination of Community Emergency Response Team (CERT) Organizations in Virginia. Quick Response Research Report, pp: 1-7.

Fritze, J.G., G.A. Blashki, S. Burke and J. Wiseman, 2008. Hope, despair and transformation: Climate change and the promotion of mental health and wellbeing. Int. J. Mental Health Syst., 2: 1-13. DOI: $10.1186 / 1752-4458-2-13$

Gist, R. and B. Lubin, 1989. Psychosocial Aspects of Disaster. 1st Edn., Wiley, New York, ISBN: 0471848948 , pp: 357.

Green, B.L. and J.D. Lindy, 1994. Post-traumatic stress disorder in victims of disasters. Psychiatric Clin. North Am., 17: 301-309. PMID: 7937361

Gruenberg, E.M., 1967. The social breakdown syndrome--some origins. Am. J. Psychiatry, 123: 1481-1489. PMID: 6025186

Haque, C.E. and D. Etkin, 2007. Preface, Natural Hazards (Special Issue on "People, Community and Resilience: Societal Dimensions of Environmental Hazards. Haque, C.E. and Etkin, D.), 41(2): 269-270.

Haque, C.E. and I. Burton, 2005. Adaptation options strategies for hazards and vulnerability mitigation: An international perspective, Mitigation Adapt. Strat. Global Change, 10: 335-353. DOI: 10.1007/S11027-005-0050-Y

Haque, C.E., 2002. Scoping of issues concerning risk reduction to all hazards in canadian non-urban communities. Office of Critical Infrastructure Protection and Emergency Preparedness, pp: 83.

Haque, C.E., D. Dominey-Howes, N. Karanci, G. Papadopoulos and A. Yalciner, 2006. The need for an integrative scientific and societal approach to natural hazards. Natural Hazards, 39: 155-157. DOI: $10.1007 / \mathrm{S} 11069-006-0020-\mathrm{Z}$ 
Haque, E., J. Lindsay, J. Lavery and M. Olczyk, 2004. Exploration into the Relationship of Vulnerability and Perception of Risk Communication and Behaviour: Ideas for the Development of Tools for Emergency Management Programs. 1st Edn., Office of Critical Infrastructure Protection and Emergency Preparedness, Ottawa, pp: 64.

Health Canada, 2004. Climate change and health: research report. Minister of health, Ottawa, pp: 124.

Henstra, D., 2006. Evaluating and Explaining Local Emergency Management Policies in Ontario. Proceedings of the Annual Meeting of the Canadian Political Science Association, Jun. 1-3, The University of Western Ontario, London, ON., pp: 1-23.

House, J.S., 2002. Understanding social factors and inequalities in health: 20th century progress and 21st century prospects. J. Health Soc. Behav., 43: 125-142. DOI: 10.2307/3090192 PMID: 12096695

Hutton, D., 2001. Psychosocial Aspects of Disaster Recovery: Integrating Communities into Disaster Planning and Policy Making. Institute for Catastrophic Loss Reduction, pp: 1-15.

Hutton, D., 2004. Psychosocial effects of a natural disaster: A post-flood assessment in the red river valley. Environ. J., 3: 27-43.

Hutton, D., C.E. Haque, P. Dhar Chowdhury and G. Smith, 2007. Impact of climate change and extreme events on the psychological wellbeing of individuals and the community and consequent vulnerability: mitigation and adaptation by strengthening community and health risk management capacity. Final Comprehensive Report prepared for the Climate Change Impacts and Adaptation Program (CCIAP). Ottawa, Earth Science Division, Natural Resources Canada, pp: 47.

International Federation of Red Cross and Red Crescent Societies, 2004. World Disasters Report: Focus on Community Resilience. Kumarian Press, Bloomfield, CT., pp: 231.

Jacobson, D.E., 1986. Types and timing of social support. J. Health Soc. Behav., 27: 250-264. DOI: $10.2307 / 2136745$

Kaniasty, K. and F.H. Norris, 1993. A test of the social support deterioration model in the context of natural disaster. J. Personality Soc. Psychol., 64: 395-408. DOI: 10.1037/0022-3514.64.3.395

Kano, M., J.M. Siegel, M.S. Hyg and L.B. Bourque, 2005. First-Aid training and capabilities of the lay public: A potential alternative source of emergency medical assistance following a natural disaster.
Disasters, 29: 58-74. DOI: 10.1111/J.03613666.2005.00274.X

Kar, G.C., 2000. Disaster and mental health. Indian J. Psychiatry, 42: 3-13.

Lazarus, R.S. and S. Folkman, 1984. Stress, Appraisal, and Coping. 1st Edn., Springer Publishing Company, New York, ISBN-10: 0826141919, pp: 456.

Leaning, J., S.M. Briggs and L.C. Chen, 1999. Humanitarian Crises: The Medical and Public Health Response. 1st Edn., Harvard University Press, Cambridge, MA., ISBN: 0674155157, pp: 379.

Lett, H.S., J.A. Blumenthal, M.A. Babyak, T.J. Strauman and C. Robins et al., 2005. Social support and coronary heart disease: Epidemiologic evidence and implications for treatment. Am. Psychosomatic Soc., 67: 869-878. DOI: 10.1097/ 01.psy.0000188393.73571.0a

Lindstrom, M., 2004. Social capital, the miniaturisation of community and self-reported global and psychological health. Soc. Sci. Med., 59: 595-607. DOI: 10.1016/J.SOCSCIMED.2003.11.006

Marsh, G. and P. Buckle, 2001. Community: The concept of community in the risk and emergency management context. Australi. J. Emergen. Manage., 16: 5-7.

McEwen, C.A., 1980. Continuities in the study of total and nontotal institutions. Ann. Rev. Sociol., 6: 143185.

DOI: 10.1146/ANNUREV.SO.06.080180.001043

McGrath, J.E., 1970. Social and Psychological Factors in Stress. 1st Edn., Holt, Rinehart and Winston, New York, pp: 352.

Mechanic, D., 1999. Mental Health and Social Policy: The Emergence of Managed Care. 4th Edn., Allyn and Bacon, Boston, ISBN-10: 0205269931, pp: 289.

Mileti, D., 1999. Disasters by Design: A Reassessment of Natural Disasters in the United States. 1st Edn., Joseph Henry Press, Washington, D.C., ISBN-10: 0309063604, pp: 376.

Mileti, D.S. and J. L. Gailus, 2004. Sustainable development and hazard mitigation in the united states: Disasters by design revisited. J. Mitigation Adaptat. Strat. Global Change, 10: 491-504. DOI: 10.1007/S11027-005-0057-4

Morrow, M., 2010. Relocating mental health care in British Columbia: Riverview Hospital Redevelopment, Regionalization and Gender in Psychiatric and Social Care. Centre for the Study of Gender, Social Inequaities and Mental Health, Vancouver, BC., ISBN: 0986615609. 
Mukherjee, P.P. and J.L. Alpert, 2006. Overview of Psychological Interventions in the Acute Aftermath of Disaster. In: Psychological Interventions in Times of Crisis, Barbanel, L. and R.J. Sternberg (Eds.). Springer Publishing Company, New York, pp: 3-35. ISBN: 0826132251

Office of Critical Infrastructure Protection and Emergency Preparedness 2001. Natural hazards in Canada. Ottawa: Office of Critical Infrastructure Protection and Emergency Preparedness, pp: 18.

Pearce, L., 2003. Disaster management and community planning and public participation: How to achieve sustainable hazard mitigation. Natural Hazards, 28: 11-228. DOI: 10.1023/A:1022917721797

Pearce, L., 2005. The value of public participation during a hazard, impact, risk and vulnerability (HIRV) analysis. J.Mitiga. Adaptat. Strategies for Global Change 10: 411-441. DOI: 10.1007/S11027-005-0054-7

PHAC, 2005a. What is the population health approach? Public Health Agency of Canada, Ottawa.

PSEPC, 2005b. Canadian disaster database. Ottawa, ON: PSEPC.

Putnam, R.D., 2000. Bowling Alone. 1st Edn., Simon and Schuster Touchstone Books, New York, ISBN10: 0743203046 , pp: 544.

Rimmer, J. H., 1999. Health promotion for people with disabilities: The emerging paradigm shift from disability prevention to prevention of secondary conditions. Phys. Ther., 79: 495-502. PMID: 10331753

Rubin, H.J. and I.S. Rubin, 2000. Community Organizing and Development. 3rd Edn., Allyn and Bacon, New York, ISBN-10: 0205261167, pp: 444.

Rubonis, A. and Bickman, L., 1991. Psychological impairment in the wake of a disaster: The disasterpsychopathology relationship. Psychol. Bull., 109: 384-399. DOI: 10.1037/0033-2909.109.3.384

Schaefer, C., J. Coyne and R.Lazarus, 1982. The health-related functions of social support. J. Behav. Med., 4: 381-406. DOI: 10.1007/BF00846149

Seguin, J. 2008. Human Health in a Changing Climate: A Canadian Assessment of Vulnerabilities and Adaptive Capacity. Health Canada, The Minister of Health, Ottawa.

Simpson, D. M., 2001. Community emergency response training (CERTs): A Recent History and Review. Natural Hazards Rev., 2: 54-63. DOI: 10.1061/(ASCE)1527-6988(2001)2:2(54)

Smith, B., C. North, R. McCool and J. Shea, 1990. Acute post-disaster psychiatric disorders: Identification of persons at risk. Am. J. Psychiatry 147: 202-206. PMID: 2301660
Smith, K. and D.N. Petley, 2009. Environmental Hazards: Assessing Risk and Reducing Disaster. 5th Edn., Taylor and Francis, New York, ISBN: 0415428637, pp: 383.

Staab, J., C. Fullerton and R. Ursano, 1999. A Critical Look at PTSD: Constructs, Concepts, Epidemiology and Implications. In: Response to Disaster: Psychosocial, Community and Ecological Approaches, Gist, R. and B. Lubin (Eds). Psychology Press, Philadelphia, PA., pp: 101-132. ISBN: 0876309988

Stansfeld, S., 2006. Social Support and Social Cohesion. In: Social Determinants of Health, Marmot, M.G. and R.G. Wilkinson (Eds.). Oxford University Press, Oxford, pp: 366-366. ISBN: 0198565895

Statistics Canada, 2001a. Population urban and rural, by province and territory 2001 Census.

Statistics Canada, 2001b. Aboriginal peoples of Canada 2001 Census.

Strike, C., P. Goering and D. Wasylenk, 2002. A population health framework for inner-city mental health. J. Urban Health, 79: 513-520. PMID: 12473695

Subramanian, S., D. Kim and I. Kawachi, 2002. Social trust and self-related health in U.S. communities: A multilevel analysis. J.Urban Health, 79: 521-534. PMID: 12473696

Thoits, P. A., 1995. Stress, coping and social support processes: Where Are We? What Next? J. Health Soc. Behav., 35: 53-79. DOI: 10.2307/2626957

Tierney, K, J., 1989. The Social and Community Contexts of Disaster. In: Psychosocial Aspects of Disaster, Gist, R. and B. Lubin (Eds.). Toronto, John Wiley and Sons Inc., Canada, pp: 11-39. ISBN: 0471848948

Wheaton, B., 1983. Stress, person coping resources and psychiatric symptoms: An investigation of interactive process. J. Health Soc. Beh., 26: 352364. DOI: $10.2307 / 2136658$

Williams, B., S. Brown, M. Greenberg and M. Khan, 1999. Risk perception in context: The Savannah River-Site stakeholder study. Risk Anal., 6: 10191035. DOI: 10.1023/A:1007095808381

World Health Organization, 1992. Psychosocial Consequences of Disasters: Prevention and Management. WHO, Division of Mental Health, Geneva, pp: 24.

WRHA, 2007. Community development framework.

Yates, S., D. Axsom, L. Bickman and G. Howe, 1989. Factors Influencing Help Seeking for Mental Health Problems after Disasters. In: Psychosocial Aspects of Disaster, Gist, R. and B. Lubin (Eds.). Wiley, pp: 357-357. ISBN: 0471848948 